\title{
Optimal scheduling of operating modes of the gas transmission system
}

\author{
Prytula N. ${ }^{1}$, Frolov V. ${ }^{1}$, Prytula M. ${ }^{2}$ \\ ${ }^{1}$ Institute of Gas Transmission PJSC Ukrtransgas \\ 16 Marshal Konev str., 61004, Kharkiv, Ukraine \\ ${ }^{2}$ Centre of Mathematical Modelling of Pidstryhach Institute for \\ Applied Problems of Mechanics and Mathematics NAS of Ukraine \\ 15 Dudayev str., 79005, Lviv, Ukraine
}

(Received 3 July 2017)

\begin{abstract}
The optimization problems of gas transmission for different optimality criteria are presented. The analysis of factors that influence both calculation of operating mode parameters and complexity of algorithms of search of their optimal values is carried out. In the course of conducting numerical experiments, some classes of problems being solved in an optimization statement are demonstrated.
\end{abstract}

Keywords: optimization, criterion of an optimality, gas transmission system, compressor station, optimization potential.

2000 MSC: $76 \mathrm{~N} 25,49 \mathrm{~J} 20$

UDC: 621.64 .029

\section{Introduction}

Optimization of operating modes of the gas transmission system (GTS) requires building algorithms of minimal complexity and fast convergence methods for solving nonlinear equations and systems taking into account technical and technological constraints. Existing uncertainty, system dimension, metrological and informational support have a significant impact on both the statement of problems and the complexity of developing approaches to finding optimal solutions. The problems of optimal scheduling arise at the stages of designing, reconstruction and overhaul of facilities and became an essential part of the system of making operational and perspective solutions in the control system control. At the stage of the problem statement, it should be taken into account that during the operation of the facilities of the gas transmission system, the coefficients of hydraulic resistance of the pipelines change and their strength characteristics deteriorate. In addition, the adequacy of the modelling of compressor stations and workshops depends on the reliability of information on the condition of gas compressor units, their gas-dynamic characteristics, which deteriorate during the operation.

Most known methods of optimization (according to different criteria) do not take into account the limited availability of existing resources (compressor station (CS) capacity, projected volume of accumulated gas in pipes, forecast of gas inlet and outlet in the GTS), the presence of control valves, topological and technological features of specific gas transmission systems and their operation conditions. In order to build effective algorithms for optimizing GTS operating modes, it is necessary to find out the optimization potential and assess the real possibilities of its achievement. The real possibilities of achieving optimal operating mode are related to the capabilities of the system of management of available resources, which will ensure not only its maintenance within the given technological limits, but also change in such limits that would provide support to the necessary degree of reliability and optimality of the system.

It should be noted that the Ukrainian gas transmission system (GTS) was designed for optimal operation under conditions of its nominal loading. Currently, the GTS works on a non-compliant 
basis, as well as non-project reverse gas supplies are used, which greatly complicated the development of methods for scheduling optimal operating modes.

In the area of optimal scheduling of operating modes that take into account the features of the real GTS or its parts there is a small number of works. Among them there should be mentioned works [1-7].

\section{The gas transmission system as an object of scheduling}

All facilities involved in the transmission and storage of gas are combined into a single technological process by pipelines with lengths from tens meters to hundreds and more kilometres and with diameters from 100 to $1420 \mathrm{~mm}$. Most sections of gas pipelines are laid at a certain depth, and a small part of them pass over the surface of the earth. The external surface of the pipes undergoes heat transfer with the external environment. The pipeline route profile is variable and may vary up to 800 meters or more for dozens of kilometres. The working pressure in the pipes reaches $7.5 \mathrm{MPa}$, and in the reservoirs of gas storages up to $12 \mathrm{MPa}$. The compressor station (CS) can consist of several workshops, which allows it to work up to three stages. Quite often, shops differ in type of gas compressor units (GCU), both in terms of capacity (from 4.0 to $27.0 \mathrm{MW}$ ) and type of engine (electric engine, gas turbine engine, gas engine) for centrifugal compressors. Many piston-type compressors operate on underground gas storage facilities. Technological piping diagrams of certain CSs can provide its work in two and three stages. The total length of main gas pipelines is more than 36 thousands kilometres.

At all underground gas storages (UGS) there are gas preparation systems for their cleaning from solid and liquid additives. Dust collectors and separators are used for this purpose. To ensure a non-destructive effect on the isolation of gas pipelines and increase their throughput, they use cooling natural gas by air cooling units (ACU), which allow cooling the gas to a temperature of 40 Celsius degree and below regardless of the season. Significant savings in fuel and energy resources can be obtained if the ACU is used to control the thermal mode of gas transmission at low ambient air temperatures. At the GTS there are a large number (thousands) of different types of shut-down and control valves. Some of them are equipped with drives for opening and closing them.

Underground gas storage facilities are available for the stable provision of transit flows and gas consumers, especially in the autumn-winter period. The gas is stored in reservoirs-collectors, which represent heterogeneous porous medium with complex geophysical structure. The depth of reservoir layers in different storage facilities is within $450-2500$ meters. The structure of the porous medium, the volumes of gas storage and the number of wells through which the gas is injected (withdrawn) for each gas storage is different.

The optimal operating mode is formed for specific input data, some of which are known with a certain accuracy. Within the precision of the input data there is a set of operating modes that do not differ significantly from the optimal one. Often, an additional condition for choosing the optimal operating mode is the condition of minimum switching in the transition from the operational to the predicted operating mode, or its resistance to the fluctuation of flow rate and gas pressure.

The information basis for scheduling the operating modes of the GTS is predicted data. The forecast is fairly accurate if the scheduling of the operating mode is within a short time interval one, or several days. The most informative and short-term forecast is the information concerning the volume of accumulated gas in the system (in subsystems and certain sections of gas pipelines) and its possible change. This enables, with scheduled switching, to accurately calculate the predicted mode without making complex calculations of the GTS operating mode in an unsteady statement.

\section{About the mathematical model of the system}

The mathematical model of the system is formed on the basis of a mathematical model of the structure of the system, mathematical and informational models of gas flows in facilities and a system of balance 
equations that connect the parameters of gas at the boundaries of various types of facilities and in the nodes of the union and distribution of flows of the system $[6,7]$.

The mathematical model of the structure of the GTS is partially directed without loops, not necessarily a connected graph $G=(V, E)$, which consists of finite numbers of vertices $V$ and edges $E$. Each edge is defined by a pair of vertices. If the vertices are connected by only one edge, then this edge will be denoted $(i, j)$. The set $V$ is the union of sets of vertices $V_{1}, V_{2}, V_{3}$, which are called inflow, outflow, and internal, respectively. The internal vertices of the graph $G=(V, E)$ of the GTS are the points of connection of pipelines and various types of facilities, branching of pipelines and changes of their geometric parameters, etc. The vertices $V_{1}, V_{2}$ are respectively gas inflows and outflows. All other facilities, which are characterized by length, are called edges (pipelines, CS, shut down and throttle valves, air cooling units, separators, etc.). Models of gas flows on the edges connect the outlet with the inlet gas flows, taking into account the parameters of external influences.

Denote $q_{i j}^{+}, q_{i j}^{+}$- the volume flow rate of gas at the inlet and outlet of the gas pipeline $(i, j)$. For steady flows these values are equal. The graph $G=(V, E)$ of the technological piping diagram of the GTS includes the graphs $G_{i j}=(V, E)(i, j) \in A_{c s}$ of the technological piping diagrams of the CS and $G_{j}=(V, E) j \in A^{+}$(gas withdrawal from the storage), or $j \in A^{-}$(gas injection into the storage) of the technological piping diagrams of the UGS. In addition, the following are known: inlet flows (sources) $-Q_{i}^{+}(t)$ with gas parameters; $P_{i}\left(t_{i}\right), \rho_{i}\left(t_{i}\right) i \in A^{+} \subset E$ Gas withdrawal $-j \in A^{-} \subset E$; The vertices of the metering of gas parameters $-\left\{P_{k}\left(t_{i}\right), T_{k}\left(t_{i}\right)\right\} k \in A_{P T} \subset E$; Volume flow rate measurements $q_{i j}^{+}(t)$ or $q_{i j}^{-}(t)$ or $q_{i j}^{+}(t), q_{i j}^{-}(t),(i, j) \in A_{q} \subset V$; Coefficients of the hydraulic resistance of the gas flows at the sections of the gas pipelines $\lambda_{i j}(t)(i, j) \in A_{\lambda} \subset V$; Parameters of the thermo-hydraulic condition of the GCU $-\eta_{\text {pol }}(i, j) \in A_{\eta} \subset V$ (a polytropical fuel efficiency of the centrifugal supercharger); The parameters of the environment for the gas pipeline sections $-T_{i j}(t), K_{i j}(t)(i, j) \in A_{g z} \subset V$, (the ambient temperature and the coefficient of heat transfer from the gas to the external environment); Environmental parameters for GCU $T_{i j}(t), P_{i j}^{b}(i, j) \in A_{q p} \subset V$, (ambient temperature and barometric pressure). We believe that the following balance equivalence is satisfied:

$$
Q_{i}^{+}(t)+Q_{j}^{-}(t)+Q_{i j}^{p}(t)+\Delta \Omega_{i j}(t)+Q_{i j}^{-}(t)=0 .
$$

Where $\Delta \Omega_{i j}$ - change of the volume of accumulated gas; $Q_{i j}^{-}$- irrecoverable gas losses due to the system's leakage; $Q_{i j}^{p}$ - withdrawal of gas for the needs of the CS (basically it is a fuel gas for gas turbine drives).

\section{General statement of the problem of optimal scheduling}

Initial conditions for the problem for operational and long-term scheduling of operating modes are formed in different ways. Long-term scheduling is based on projected averaged values of the components of the gas balance in the system and the consideration of planned, preventive and repair works. The withdrawal of gas from the system is calculated on the basis of a statistical model that takes into account all the main factors of influence on its value. Operational scheduling (up to one day) is based on measured data and updated data on the volumes of transit and import of gas at all points of inflow (outflow) into the system (from the system).

In the statement of the problem, the following designations are used: $(i, j)$ - the edge of the graph $G(X, Y)$ ( $i$ and $j$ - vertices numbers), $Q_{i}^{+}, Q_{i}^{-}, T_{i}, P_{i}, q_{i j}, \rho_{0},\left\{m_{i}\right\}$ - the injection (flow rate), withdrawal (flow rate), temperature, gas pressure, gas flow to the edges, gas density under normal conditions, mass gas composition, etc. For all the below-stated problems, mathematical models of all facilities and technical and technological constraints, as well as the state of control and shut down valves (various types of valves, Mokveld control valves, reducers, etc.) are considered given.

We consider that a mathematical model of the structure and a mathematical model of gas flows in facilities are given. The inlets are: gas sources with values $\left(Q_{i}^{+}, T_{i}\right)$, or $\left(Q_{i}^{+}, T_{i}, \rho_{i 0}\right)$ (possible 
assignment of total volumes at inlets of transit and imported gas) or $P_{i}, Q_{i}^{+}, T_{i}, \rho_{i 0}, T_{i r},\left\{m_{i}\right\}$; Gas withdrawals with values $Q_{j}^{-}$, or $\left(Q_{j}^{-}, T_{j r}\right)$, for each edge $(i, j)$ of type CS one of the values is given $P_{1}, P_{2}, q_{i j}, \varepsilon$. Existing technological constraints form $D(\bar{r})$ - a permissible set of operating modes of the GTS and $D(\bar{u})$ - an acceptable set of controls.

Need to find: $P_{i}, T_{i}\left(i=1,2, \ldots, n_{G}\right)$ - at all vertices of graphs $G, G_{k} ; q_{i j}, T_{r}(i, j), \rho(i, j)-$ flow rate, dew point and gas density under normal conditions for all edges $(i, j) \in G(X, Y) ; Q_{k}^{-}$, $n, N, \varepsilon, \delta, W, W_{z}$ - fuel consumption and energy resources, GCU number (if required by stages), supercharger revolutions, gas compression ratio, distance from the zone of surging, total productivity, residual productivity for all involved in the CS operating mode.

When satisfied the specified conditions:

- degree of stability aof the GTS operating mode (given distance from the boundary of all the centrifugal superchargers $\frac{q_{i}^{j}}{q_{i \min }^{j}} \geqslant a$, where $q_{i}^{j}$ - volume flow rate of $i$-th GCU of $j$-th CS),

- total fuel gas consumption $\sum_{j} Q_{j}^{-} \rightarrow \min$.

An additional condition for operational scheduling of operating modes may be a given volume of accumulated gas in the GTS and its distribution in interconnected subsystems or sections of main gas pipelines.

In all cases, technical and technological constraints must be satisfied.

\section{Algorithmic problems and approaches to its solution. On the idea of the method of calculation of optimal operating mode parameters}

When solving the problem of scheduling a system with thousands of facilities, the accuracy of the obtained results, the time of their receipt and the level of automation of the process of solving to complex of interrelated problems is important. The accuracy of solving such an optimization problem should be correlated with the accuracy of the prediction of the input data and the accuracy of the identification of the parameters of the gas flow models. High-precision optimization in limited and distributed resources, especially for operational scheduling, requires significant computing resources. It should be noted that complete automation of the process of solving such a problem is a rather complicated problem. The complexity of the problem is significantly influenced, in particular, by finding the optimal topology in conditions of the unloaded GTS of Ukraine. The conditions of the change of the topology are established only in the course of conducting numerical experiments on real data. It is well automated for many threaded gas pipelines with a minimal enumeration of options if pre-set areas of optimality of their operation.

To obtain substantiated results it is necessary: to cover all the completeness of factors that significantly affect the gas-dynamic processes; To use proven facts obtained under known assumptions or conditions; take into account the limitations and variability of available resources that can ensure the optimal realization of the optimization potential to the maximum extent possible.

The optimal scheduled operating mode can be achieved with:

- redistribution of flow rate between workshops of multi-show CS and minimization of the number of working GCU in CS;

- redistribution of the total volume of accumulated gas along the gas main (GM);

- regulation of gas flows between GMs with different nominal pressures;

- redistribution of flows between different threads of multi-threaded GMs and the work of certain CS in idle mode;

- the choice of the temperature mode (cooling of gas at the outlets of the CS by choosing the number of fans included and the speed of their rotation) of gas transmission, which reduces energy of transmission and increases the throughput capacity of the GM.

There is a certain class of optimization problems that need to be solved during the reconstruction of the GCU, CS, the installation of additional inter-system jumpers, the organization of reverse gas 
supplies, etc. The result of solving such problems - the choice of parameters of facilities, the assessment of the payback of measures on the criteria of energy saving and reliable operation, etc.

The developed approach to solving problems for the GTS of complex structure is as follows. The algorithmic assurance of the optimization of the structural elements of the GTS into which it is uniquely divided (linear, star, and contour-type structures) is developed. To reduce the complexity of the algorithms, numerical experiments were conducted to identify the optimization potential and to establish the properties of optimal operating modes. The decomposition of the system into simpler structural elements is also made taking into account the parameters of the Mokveld valves and reducers.

Another decomposition has been carried out on conditionally independent structural elements multi-shop CS with combined inlets and outlets, underground gas storage facilities and two- and threethread main gas pipelines.

\section{Certain examples of the application of the developed software}

The development of software modules for optimal scheduling of operating modes will ensure the fulfilment of the functions of the operator of the gas transmission system regarding:

- distribution of capacity and access to power at physical points of inlet or outlet on interstate connections between the auction participants;

- balancing of the system and managing overloads in the gas transmission system;

- hydraulic analysis of the system for the needs of the market in the new transmission infrastructure, the results of which are taken into account in the preparation of development plans;

- efficient and reliable operation of the GTS in conditions of repair of networks, installations and facilities of the gas transmission system in conjunction with other gas systems.

Problem 1. Calculation of volumes of free capacities at a specific inlet (outlet) into the system (from the system); for certain gas pipeline, the system of gas pipelines; for certain workshops, CS's. For certain UGSs or a group of technologically connected UGSs. For parts of the technological piping diagram. For the entire GTS in different scenarios of its operation (in terms of volume flow rate of export, import, gas extraction, consumption structure), on the one hand, as well as in changing the volumes and places of gas inflow (export + import) in the east of the system and locations and distribution volume flow rates in the west of the system. For the case of peak capacity operation taking into account possible non-emergency situations.

Problem 2. Modernization of the GTS to ensure the operation of the GTS in the conditions of the forecast scenario (see Table 1 ).

Table 1. Scenario of operating mode of Ukraine's GTS.

\begin{tabular}{|c|c|c|c|}
\hline $\begin{array}{c}\text { Type of inflow/outflow } \\
\text { vertex }\end{array}$ & $\begin{array}{c}\text { Volume flow } \\
\text { rate, } \\
\mathrm{G} \cdot \mathrm{m}^{3} / \text { year }\end{array}$ & $\begin{array}{c}\text { Summer scenario } \\
\text { April-September }), \\
\mathrm{G} \cdot \mathrm{m}^{3} / \text { season }\end{array}$ & $\begin{array}{c}\text { Winter scenario } \\
\text { (October-March), } \\
\mathrm{G} \cdot \mathrm{m}^{3} / \mathrm{season}\end{array}$ \\
\hline Inflow in the system & 60.5 & 30.25 & 30.25 \\
\hline Extraction & 25.5 & 12.75 & 12.75 \\
\hline UGS withdrawal & 10 & - & 10 \\
\hline Consuming & 51 & 15.5 & - \\
\hline UGS injection & 10 & 10 & 17.5 \\
\hline Transit & 35 & 17.5 & \\
\hline
\end{tabular}

One of the main problems arising in the operation of the Ukrainian gas transmission system is the reduction of the cost of fuel and energy. There are two ways - optimization of compressor stations and their modernization. Taking into account the technical condition of compressor equipment on most main gas pipelines (in the real conditions of operation of the CS the efficiency of its GCU is about 
$20 \%$, which is much lower than the modern facilities, which makes up $36-40 \%$ ). As we see, the park GCU needs to be practically completely updated.

Data on the load of GTS, identified by the draft of energy strategy of Ukraine until 2030, are given in Table 1. In Ukraine as in most European countries, there is a significant difference between summer and winter operating modes. We will assume that the winter and summer operating modes continue for exactly half a year. The main difference between these seasons is the volume of gas consumption. This difference in consumption is offset by gas volumes that are taken from underground gas storage.

The calculations of the operating modes are carried out on detailed technological piping diagrams. In one of the options, the operating mode is formed by the method of disconnecting part of the gas pipeline sections in such a way that it does not create problems for gas consumers. The total length of sections of gas pipelines of all diameters in the technological piping diagram is $36511478.43 \mathrm{~m}$. The sum of the lengths of sections that did not participate in the implementation of the 3rd operating mode was $1957.143 \mathrm{~km}$.

Table 2. CS operating modes in conditions of switching off maximum number of pipeline sections in the summer forecasted operating mode.

\begin{tabular}{|c|c|c|c|c|c|}
\hline CS name & Operating mode & $\begin{array}{c}\text { Qfuel, } \\
\text { million } \mathrm{m}^{3} / \text { day }\end{array}$ & Pomp & $\begin{array}{c}\mathrm{Q}, \\
\text { million } \mathrm{m}^{3} / \text { day }\end{array}$ & $\varepsilon$ \\
\hline CS "Zinkiv" & [1]1,2,3:235-21-1[4969] & 0.25 & 1.5522 & 59.39 & 1.3000 \\
\hline CS "Reshetylivka" & [1]1,2,3:235-21-1[4446] & 0.23 & 1.5198 & 59.30 & 1.2369 \\
\hline CS "Kirovogradska" & {$[1] 1,2,3: 235-21-1[3608]$} & 0.15 & 1.2330 & 41.99 & 1.2000 \\
\hline CS "Bogorodchany" & [2]1,2:PCL804-2/36[3261] & 0.17 & 1.3901 & 45.73 & 1.2127 \\
\hline CS "Golyatyn" & [1]1:PCL804-2/36[3360] & 0.14 & 1.9421 & 35.81 & 1.2000 \\
\hline CS "Tyraspil" & {$[1] 1: \mathrm{H}-16-76 / 1,44[5248]$} & 0.09 & 1.7552 & 34.82 & 1.2000 \\
\hline CS "Grebinka" & {$[1] 1,2: 650-21-2[3672]$} & 0.24 & 1.1210 & 58.54 & 1.3500 \\
\hline CS "Sofiyivka" & [1]1,2:PCL804-2/36[3599] & 0.27 & 1.1993 & 58.67 & 1.3000 \\
\hline CS "Illinci" & [2]4,5:235-21-1[5192] & 0.00 & 1.6859 & 53.95 & 1.3000 \\
\hline CS "Dykanka" & [1]1,2,3,4,5:6,3ГЦ2-206/24-43[8619] & 0.24 & 1.9182 & 31.36 & 1.4742 \\
\hline CS "Lubny" & {$[1] 1,2,3: 370-17-1[5523]-[1] 6,7: 370-17-1[6226]$} & 0.23 & 1.7100 & 34.19 & 1.3820 \\
\hline CS "Yagotyn" & {$[2] 5,6: 370-18-1[5256]-[2] 2,3: 370-18-1[4608]$} & 0.17 & 2.0596 & 34.55 & 1.4000 \\
\hline CS "Boyarka" & [1]1,2,3:280-11-6[8539] & 0.00 & 1.3372 & 26.70 & 1.2603 \\
\hline CS "Berdychiv" & {$[1] 1: 520-12-1[3686]-[1] 4: 520-12-1[3610]$} & 0.09 & 1.7390 & 23.73 & 1.2625 \\
\hline CS "Krasyliv" & {$[1] 2: 520-12-1[3409]-[1] 3: 520-12-1[3259]$} & 0.08 & 1.3597 & 22.71 & 1.2930 \\
\hline CS "Dolyna" & [3]13:16ГЦ2-395/53-76С[5191] & 0.09 & 1.3163 & 20.52 & 1.4425 \\
\hline
\end{tabular}

The main columns are the volume flow rate of fuel gas (Qfuel), the operating mode ([1] 1: 520-12-1 [3686] - [1] 4: 520-12-1 [3610]), the distance from the surge zone (Pomp), gas flow rate through the CS (Q), gas compression ratio (CE), gas pressure on the inlet of the GCU (Pin), gas pressure on the outlet, gas temperature on the inlet of GCU (Tin), on the outlet (Tout).

The structure of the operating mode string [2] 9, 10: НЦ-16/56 [4692], 11: НЦ-16/41 [4872] - [2] 12, 13: НЦ-16/56 [4562], 14: НЦ-16/76 [4564], [4] 24, 25: Ц-6, 3В/29 [6086] - [4] 27, 28: Ц-6,3В/41 [6511] is as follows - [No. Workshop] No. GCU1, No. GCU2: GCU type [revolutions] - [No. Workshop] No. GCU1, No. GCU2 : GCU type [revolutions], [No. Workshop] No. GCU1, No. GCU2: GCU type [revolutions] - [No. Workshop] No. GCU1, No. GCU2 : GCU type [revolutions], where "_" denotes series connection, and "," - denotes parallel connection.

Table 3. Estimation of the minimum amount of funding for modernization of the CS.

\begin{tabular}{|c|c|c|c|c|c|}
\hline No. & Variants & $\begin{array}{c}\text { Number } \\
\text { of CS's }\end{array}$ & $\begin{array}{c}\text { Total capacity } \\
\text { of CS's(MW) }\end{array}$ & $\begin{array}{c}\text { The cost of upgrading } \\
1 \text { MW capacity in USD }\end{array}$ & $\begin{array}{c}\text { The total cost } \\
\text { Modernization in USD }\end{array}$ \\
\hline 1 & Summer operating mode & 10 & 234.0 & 928564.0 & 339508000.0 \\
\hline 2 & Winter operating mode (reverse) & 13 & 290.0 & 928564.0 & 420758000.0 \\
\hline 3 & $\begin{array}{c}\text { Summer (with minimal number } \\
\text { of pipeline sections) }\end{array}$ & 16 & 375.0 & 928564.0 & 544078000.0 \\
\hline
\end{tabular}

When calculating the total cost of modernization of the CS, it is considered that the average capacity of GCU in the operating mode is close to $80 \%$, and also added $25 \%$ of backup capacity of the GCU at the CS. 


\begin{tabular}{|c|c|c|c|c|c|c|c|c|c|}
\hline Ukraine & 6.62629 & LTG & 1,41233 & PTG & 3.22117 & CHTG & 0,360803 & KTG & 2,93475 \\
\hline$\square$ Inflow & 307,081 & $\square$ Inflow & 65,204 & $\square$ Inflow & 235,983 & $\square$ Inflow & 174,947 & $\square$ Inflow & 156,223 \\
\hline - Through pipelines & 194,287 & - From gas fields & 1,246 & - From gas fields & 0 & - From gas fields & 1,621 & - From gas fields & 34,027 \\
\hline - Withdraw from UGS & 58,176 & - from Beltransgas & 14,52 & - From LTG & 42,7957 & - From KTG & 119,433 & - Withdraw from UGS & 2,28 \\
\hline - From gas fields & 37,698 & - Withdraw from UGS & 46,368 & - Withdraw from UGS & 9,528 & - From DTG & 53,8928 & - From Gasprom & 117,461 \\
\hline - Reverse & 16,92 & - From KTG & 0 & - From Khtg & 11,75 & - From KHTG & 0 & - From other transgas & 2,455 \\
\hline — Outflow & 313,707 & - From PTG (injection & 0 & - From Chtg & 158,06 & — Outflow & 174,586 & — Outflow & 153,288 \\
\hline - Export & 227,652 & - Reverse & 3,07 & - Reverse & 13,85 & - ToKHTG & 0 & - To CHTG & 119,433 \\
\hline - Moldova & 10,584 & $\square$ Outflow & 63,7917 & $\square$ Outflow & 232,762 & - Ukraine's consumpl & 14,921 & - Ukraine's consumpt & 32,9166 \\
\hline - Russia & 0 & - Export & 6,984 & - Export & 220,668 & -Auxiliaries & 1,41358 & -Auxiliaries & 0,938472 \\
\hline - Ukraine's consumpt & 71,7909 & - Ukraine & 13,971 & - Ukraine's consumpti & 0 & - ToPTG & 158,252 & - ToLTG & 0 \\
\hline - Production-technolc & 3,68051 & - Auxiliaries & 0.041 & -Auxiliaries & 1,28746 & - ToKTG & 0 & - Withdraw into UGS & 0 \\
\hline \multirow[t]{4}{*}{ - Iniection into UGS } & 0 & - ToPTG & 42,7957 & - Moldova & 10,584 & - To DTG (reverce) & 0 & - Kurska obl. & 0 \\
\hline & & - injection into UGS & 0 & - Injection into UGS & 0 & - GMS Novopskov-S & & - transit 0.JSC"Ukma & \\
\hline & & & & - ToLTG (injection) & 0 & & & & \\
\hline & & & & - CS Tarutyne & 0,222748 & & & & \\
\hline
\end{tabular}

Fig. 1. Balanced data of PJSC "Ukrtransgaz" and its regional departments. Units in million $\mathrm{m}^{3}$ per day.

The results are presented in a diagram. The main parameters of the diagram are the volume flow rates of gas flows along the main gas mains, the gas pressure at the inlets and outlets of all the involved CS's, the number of GCUs by types of CS that are included in the operating mode (Fig. 2).

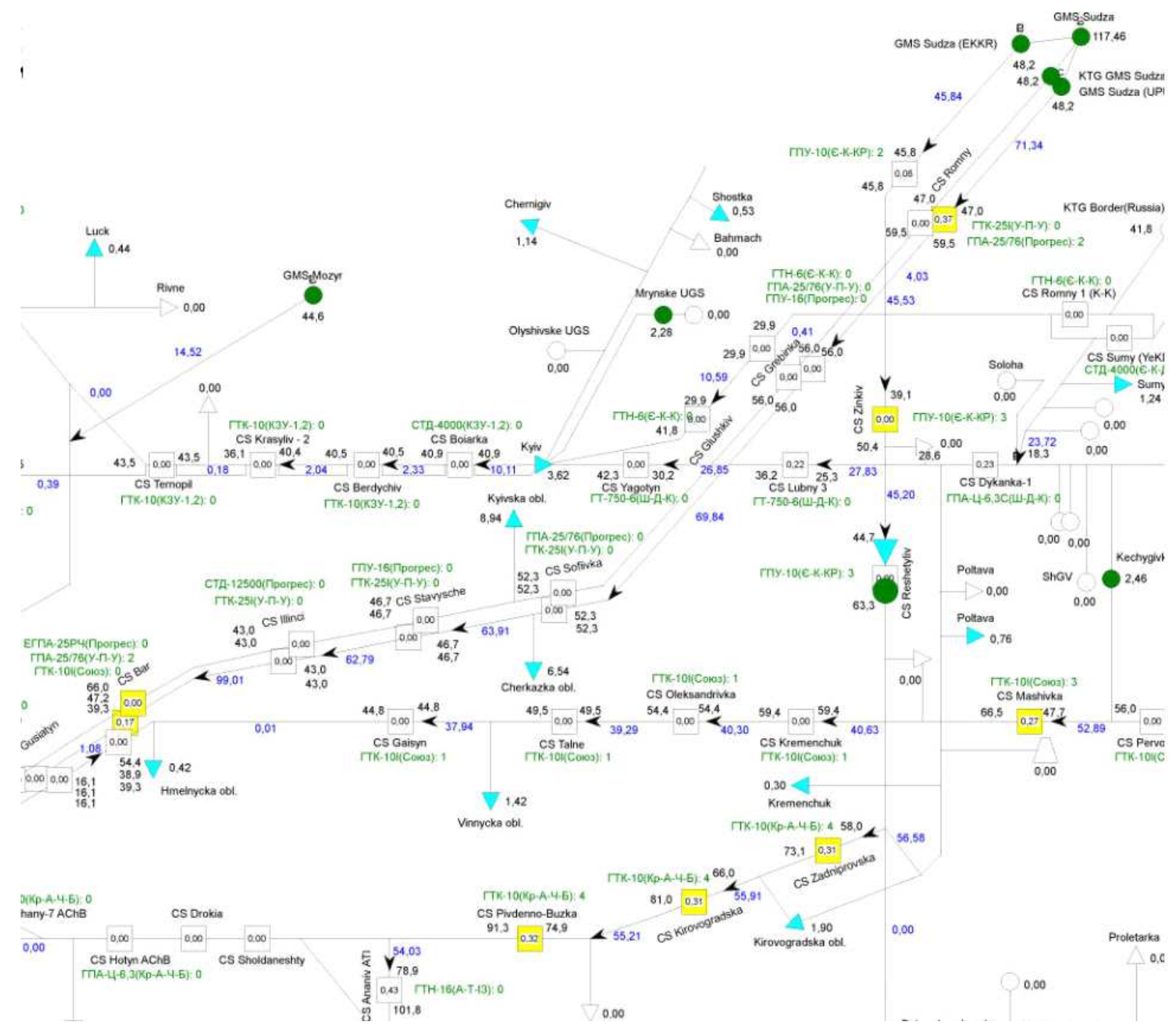

Fig. 2. Results of modelling and optimization of operating modes are presented in the diagram. 


\section{Conclusions}

Maintaining the optimal operating mode of the GTS in conditions of its significant incomplete loading is impossible using mainly technical means of control of GCUs and CS's. Firstly, no technical means make it possible to detect and assess the potential of saving fuel and energy resources, and secondly, to find parameters for control gas flows in order to maximize the use of this potential. With the help of technical means, it is possible to automate the process of transition operating modes from the operating to the optimal scheduled operating mode $[8,9]$. The potential of optimization both for certain facilities and for the system as a whole is constantly changing. The use of capacity requires a preliminary assessment. It is important to find the best ways to implement it. To find the optimal distribution of flows in the system with a complex topology, there are no universal approaches that would work reliably and quickly in the conditions of constant change of the topology, input data and the existing level of uncertainty of the input data. The main goal in the process of testing the developed algorithmic software is to ensure minimal intervention in the process of building optimal operating mode and reduce the complexity of the algorithms.

[1] Kulik V.S. Alhoritm optimizatsii transporta haza cherez razvetvliennuiu GTS. Truboprovodnyi transport: teoriia i praktika. 2, 22-25 (2014), (in Russian).

[2] Sardanashvili S. A. Rascietnyie metody algoritmy. Moscow, GUP Izdatielstvo «Neft i gaz» RGU nefti i gaza (2005), (in Russian).

[3] Selezniev V.E., Alioshin V.V., Klyshin G. S. Metody s tekhnolohii chyslennogo modelirovaniia gazoprovodnykh systiem. Moscow, Editorial URSS (2002), (in Russian).

[4] Sukhariev M. G., Stavrovskii Ye. R. Optimizatsiia sistem transporta gaza. Moscow, Nedra (1975), (in Russian).

[5] SIMONE Research Group s.r.o. Equations and Methods, Version 5.6. May 2007.

[6] Prytula N.M. Rozrakhunok parametriv potokorozpodilu hazu v hazotransportnii systemi (statsionarnyi vypadok). Fizyko-matematychne modeliuvannia ta informatsiini tekhnolohii. 5, 146-155 (2007), (in Ukranian).

[7] Prytula N. M. Zadachi optymizatsii potokorozpodilu v hazotransportnykh systemakh. Visnyk Natsionalnoho universytetu "Lvivska politekhnika" Kompiuterni nauky ta informatsiini tekhnolohii. 604, 220-227 (2007), (in Ukranian).

[8] Prytula N. Mathematical modelling of dynamic processes in gas transmission. Econtechmod. An international quarterly journal. 4 (3), 57-63 (2015).

[9] Kersting R., Shaibe D., Shrieder P., Vaiman A. Avtonomnaia sistema Online-GANESI dlia zadach upravleniia gazoprovodnoi setiu. Gwf - Gas/Erdgas $125-1984$. 


\title{
Оптимальне планування режимів роботи газотранспортної системи
}

\author{
Притула Н. ${ }^{1}$, Фролов В. ${ }^{1}$, Притула M. ${ }^{2}$ \\ ${ }^{1}$ Філія «Науково-дослідний інститут транспорту газу» ПАТ «УКРТРАНСГАЗ» \\ вул. Маршала Конєва, 16, 61004, Харків, Україна \\ ${ }^{2}$ Центр математичного моделювання Інституту прикладних проблем механіки $і$ математики \\ iм. Я. С. Підстригача НАН України \\ вул. Д. Дудаєва, 15, 79005, Львів, Украӥна
}

Сформульовано оптимізаційні задачі транспортування газу для різних критеріїв оптимальності. Проаналізовано фактори, які впливають як на розрахунок режимних параметрів, так і складність алгоритмів пошуку їхніх оптимальних значень. Під час проведення числових експериментів продемонстровано окремі класи задач, які розв'язані в оптимізаційній постановці.

Ключові слова: оптимізація, критерій оптимальності, газотранспортна система, компресорна станція, потенціал оптимізацї.

2000 MSC: $76 \mathrm{~N} 25,49 \mathrm{~J} 20$

Удк: 621.64 .029 